\title{
Lucro por Ação
}

\author{
Gabriel Moreira Campos \\ Mestrando em Controladoria e Contabilidade da FEA/USP \\ Professor da Universidade Federal do Espírito Santo - UFES \\ Luciano Márcio Scherer \\ Mestrando em Controladoria e Contabilidade da FEA/USP
}

RESUMO

ABSTRACT

Este trabalho tem por objetivo demonstrar os principais conceitos acerca do Lucro por Ação (Earnings per Share), o qual se apresenta como um quociente de grande utilidade nas entidades.

Serão demonstrados aspectos sobre o assunto presentes no Brasil, bem como as normas aplicáveis nos Estados Unidos, emanadas do Financial Accounting Standards Board (FASB), e as normas internacionais, emanadas do International Accounting Standards Committee (IASC). De forma a possibilitar uma visualização mais completa dos conceitos envolvidos, serão desenvolvidos exemplos de sua aplicação.

O Lucro (Resultado) por Ação pode ser calculado em sua forma básica e em sua forma diluída. Na forma básica, não são considerados os efeitos dos instrumentos potencialmente dilutivos, ao passo que, no cálculo do Lucro (Resultado) por Ação Diluído, são. Como instrumentos financeiros potencialmente dilutivos temos as ações preferenciais conversíveis, as debêntures conversíveis e os bônus de subscrição, que podem ser convertidos em ações ordinárias, caracterizando, assim, o próprio potencial dilutivo desses instrumentos.

Dessa forma, o trabalho em questão foi dividido em três partes principais, sendo que nas duas últimas constam os referidos exemplos de cálculo do Lucro por Ação em sua forma básica e em sua forma diluída:

- aspectos observados no Brasil;

- normas emanadas do FASB;

- normas emanadas do IASC.

Palavras-Chave: Lucro por Ação, Resultado Diluído por Ação, Financial Accounting Standards Board (FASB), International Accounting Standards Committee (IASC) e Norma Internacional de Contabilidade (IAS).
The objective of this paper is to demonstrate the principal concepts about Earnings per Share, which is presented as a quotient of great usefulness for the companies.

The subject is presented in three parts: in the first part, we will demonstrate relevant aspects that are present in Brazil. In the second part, the applicable standards in the United States will be discussed, which are issued by the Financial Accounting Standards Board (FASB). In the third part, the international standards are dealt with, which are issued by the International Accounting Standards Committee (IASC). In order to make it possible to visualize the concepts involved in a more complete way, examples of their application will be developed.

Earnings per Share can be calculated in its basic form and in its diluted form. In the basic form, the effects of the potentially diluted instruments are not considered, while, in the calculation of the Diluted Earnings per Share, they are. Examples of potentially diluted financial instruments are convertible preferred stocks, convertible debentures and subscription bonuses, which can be turned into ordinary stocks, characterizing in this way the diluted potential of these instruments.

Key words: Earnings per Share, Diluted Earnings per Share, Financial Accounting Standards Board (FASB), International Accounting Standards Committee (IASC) and International Accounting Standards (IAS). 


\section{INTRODUÇÃO}

O Lucro por Ação (LPA) é um quociente amplamente utilizado pelos investidores nos EUA e Europa para medir a rentabilidade de uma entidade.

Seu propósito é indicar quão lucrativo se apresentou um empreendimento pela utilização dos recursos disponibilizados pelos acionistas. Além disso, Hendriksen e Van Breda (1999: 500) salientam que sobre o mesmo reside uma "(...) crença de que contém informação útil para a elaboração de predições a respeito de dividendos por ação e preços de mercado futuros."

Em sua forma simplificada, o Lucro por Ação é obtido da divisão do lucro (prejuízo) líquido do exercício pelo número de ações ordinárias em circulação (no final do exercício, segundo a prática brasileira, e em função do número médio de ações no caso dos Estados Unidos e Europa). O cálculo do LPA pode tornar-se mais complexo nas hipóteses de existência de instrumentos financeiros diversos, tais como ações preferenciais conversíveis, debêntures conversíveis e bônus de subscrição, os quais podem ser convertidos em ações ordinárias. Esses instrumentos, potencialmente conversíveis em ações ordinárias, são chamados de instrumentos financeiros dilutivos, e o cálculo do LPA ignorando esses instrumentos pode tornar o número resultante enganador. Além disso, a falta de padronização na forma como esses instrumentos são incluídos no cálculo do LPA faz com que a comparabilidade entre entidades se torne bastante difícil.

\section{ASPECTOS OBSERVADOS NO} BRASIL

No Brasil, a Lei oㅜ 6.404/76, em seu artigo 187, estabelece a obrigatoriedade da divulgação do lucro ou prejuízo líquido por ação do Capital Social. Devese destacar que, até o presente momento, não existe por parte do Conselho Federal de Contabilidade (CFC) qualquer normatização sobre o assunto, contribuindo assim para a falta de harmonização nos procedimentos encontrados nas demonstrações contábeis publicadas no país. Espera-se que o grupo de trabaIhos nomeado pela Portaria CFC 10/00, de março de 2000 , inclua o assunto em sua pauta de discussões.

De forma geral, o cálculo desse quociente tem sido feito em sua forma mais simplista pelas empresas no Brasil, ou seja, mediante a simples divisão do lucro ou prejuízo líquido do exercício pelo número de ações que compõem o Capital Social da entidade ao final do período.

ludícibus et alli (1995: 550-551) destacam que o cálculo do Lucro por Ação pode tornar-se complexo nos casos em que a entidade apresentar uma estrutura complexa de capital e nos casos de aumento de capital durante o exercício. Os autores apresentam, na referida obra, uma série de exemplos que demonstram situações que tornam complexo o cálculo do Lucro por Ação. Tais exemplos são bastante próximos aos apresentados quando da discussão das normas do FASB e do IASC, de tal forma que os exemplos demonstrados quando da apresentação desses tópicos cobrem os apresentados pelos autores do Manual de Contabilidade das Sociedades por Ações.

\section{NORMAS DO FASB}

Em fevereiro de 1997, o FASB emitiu o Statement on Financial Accounting (SFAS) 128, que substituiu o Accounting Principles Board (APB) 15. O SFAS 128 representou esforços para a aproximação das normas contábeis norte-americanas, referentes ao Lucro por Ação, com as normas internacionais emanadas do IASC. Dessa forma, todas as entidades abertas norte-americanas, e as que desejarem lançar seus títulos nos Estados Unidos, devem calcular e apresentar seu LPA de acordo com as exigências do SFAS 128.

Ainda em fevereiro de 1997, o FASB emitiu o SFAS 129, que estabelece normas de disclosure a respeito da estrutura de capital das entidades. Esse pronunciamento mantém exigências de disclosure contidas no APB 10, 15 e SFAS 47; entretanto, reuniu todas as normas relacionadas à evidenciação de informações em relação à estrutura de capital de uma entidade em apenas um único pronunciamento. O SFAS 129 é aplicável a todo tipo de entidade, quer sejam abertas, quer sejam fechadas. Nele, as entidades são obrigadas a evidenciar os direitos de cada tipo de instrumentos financeiros em circulação emitidos por elas.

\subsection{Conceitos, Regras e exemplos}

\subsubsection{Estrutura Simples dE CAPITAL}

Estrutura simples de capital é aquela que ocorre 
em entidades onde somente existem ações ordinárias em circulação. Para essas entidades, é necessário demonstrar apenas o Lucro por Ação Básico (LPAB).

O valor do LPAB numa entidade que apresente uma estrutura simples de capital é obtido da divisão do lucro ${ }^{1}$ disponibilizado aos acionistas, portadores de ações ordinárias, no numerador pelo número médio ponderado de ações ordinárias em circulação durante o exercício a que se refere a demonstração contábil no denominador. Saliente-se que no caso do Brasil o LPA é calculado mediante a divisão do lucro ou prejuízo líquido do exercício pelo número de ações que compõem o Capital Social da entidade ao final do período.

\subsubsection{Determinação do numerador}

O lucro disponibilizado aos acionistas portadores de ações ordinárias deve ser deduzido dos direitos atribuídos aos acionistas portadores de ações preferenciais. A dedução corresponde ao total de direitos pagos ou disponibilizados aos acionistas portadores de ações preferenciais durante o período a que se referem as demonstrações contábeis. Isso ocorre pelo fato de que, nos Estados Unidos, as ações preferenciais são consideradas como títulos de crédito, e normalmente remuneram seus portadores com um percentual específico. Essa remuneração não é considerada uma despesa financeira; entretanto, para fins de cálculo do LPA, deve ser considerada como tal.

Se as ações preferenciais forem cumulativas, os direitos atribuíveis aos acionistas portadores de ações preferenciais devem ser deduzidos do lucro do exercício a que se referem as demonstrações contábeis, mesmo que não tenham sido declarados. No caso de as ações preferenciais não serem cumulativas, os direitos atribuíveis aos acionistas portadores de ações preferenciais somente seriam deduzidos do lucro líquido caso houvessem sido declarados. Direitos de exercícios anteriores que se encontram com seu pagamento em atraso não influenciam o cálculo do LPA para o exercício corrente, pois já foram incluídos no cálculo do LPA dos exercícios em que está ocorrendo a falta de pagamento.

\subsubsection{Determinação do denOMinador}

O número médio ponderado de ações ordinárias em circulação durante o exercício a que se referem as demonstrações contábeis consiste na média aritmética ponderada do número de ações em circulação, e assumidas como se em circulação, para fins de cálculo do LPA. Existem algumas transações cujos efeitos afetam diretamente o cálculo dessa média de ações ordinárias em circulação. O SFAS 128 apresenta aspectos de tratamento de algumas dessas transações, dentre as quais são mais comuns:

a) emissão de novas ações ordinárias => aumento do número de ações em circulação pelo número de ações emitidas durante o período em que permaneceram em circulação no exercício a que se referem as demonstrações contábeis. Tal procedimento se explica pelo fato de que essas ações emitidas ao longo do exercício contribuíram para os resultados apenas no período em que permaneceram em circulação, e não durante todo o exercício;

b) recompra de ações (ações em tesouraria) => decréscimo do número de ações em circulação pelo número de ações recompradas durante o período em que permaneceram em circulação no exercício a que se referem as demonstrações contábeis. Da mesma forma que a emissão de novas ações ordinárias, as ações recompradas contribuíram para os resultados da entidade apenas para o período em que permaneceram em circulação;

c) conversão de instrumentos financeiros diversos em ações ordinárias $=>$ aumento do número de ações em circulação pelo número de ações convertidas, ou assumidas como se fossem convertidas, durante o período em que permaneceram em circulação no exercício a que se referem as demonstrações contábeis;

d) split de ações => o desdobramento de ações deve ser reconhecido retroativamente desde 0 início do exercício a que se referem as demonstrações contábeis, independentemente da data em que tenha de fato ocorrido. A razão para tal

\footnotetext{
${ }^{1}$ Nesta parte do artigo, para fins de simplificação, adotou-se sempre a expressão lucro por ação. Dessa forma, um prejuízo por ação pode ser entendido como sendo um “lucro negativo" por ação.
} 
procedimento é que uma ação desdobrada não apresenta efeitos na participação das ações ordinárias em relação ao Capital Social total. Uma diluição no LPA em decorrência de split de ações pode dar a impressão errônea de um declínio na rentabilidade, quando de fato ocorreu apenas um aumento do número de ações ordinárias em circulação em decorrência do desdobramento de ações;

e) reverse split de ações $=>$ decréscimo do número de ações em circulação pela diminuição do número de ações como se ocorrida no início do exercício a que se referem as demonstrações contábeis;

f) fusão de empresas (pooling of interest) => nas situações de business combination entre duas entidades em que a modalidade tenha sido o pooling of interest, o resultado da entidade adquirida é considerado no resultado do exercício da empresa adquirente para o ano todo. Dessa forma, para fins de cálculo do LPA, ocorre um aumento do número de ações ordinárias em circulação pelo número de ações ordinárias da companhia adquirida como se fossem emitidas desde o início do período a que se referem as demonstrações contábeis da empresa adquirente;

g) aquisição de empresas (purchase) => nesse caso, o resultado da empresa adquirida somente será considerado no resultado do exercício da empresa adquirente a partir da data efetiva da aquisição. Dessa forma, para fins de cálculo do LPA, ocorre um aumento do número de ações ordinárias em circulação pelo número de ações ordinárias da companhia adquirida como se fossem emitidas na data de aquisição pela empresa adquirente.

Existem inúmeras outras situações que afetam a determinação do denominador da equação do LPA. Entretanto, as demonstradas acima são as mais relevantes. Existem ainda situações específicas, que caracterizam a ocorrência de uma estrutura complexa de capital em determinada entidade, as quais serão vistas posteriormente.

\subsubsection{EXEMPLO DE CÁLCULO DO LPA EM UMA ESTRUTURA SIMPLES DE CAPITAL}

Têm-se os seguintes dados:

a) Informações do numerador:

- Lucro Operacional de \$281.000;

- Itens Extraordinários (prejuízos) de \$64.000;

- Lucro Líquido do Exercício de \$217.000;

- Remuneração das ações preferenciais cumulativas de 10\% (1.000 ações preferenciais emitidas e em circulação, cada uma cotada a \$250).

b) Informações do denominador:

- 200.000 ações ordinárias em circulação desde 01/01/X1;

• 50.000 ações emitidas em 01/04/X1;

- 30.000 ações emitidas pela subscrição de $12 \%$ dos dividendos declarados em 01/07/ $\mathrm{X} 1$;

- 40.000 ações recompradas para tesouraria em 01/10/X1.

Em relação ao numerador, os direitos atribuíveis aos acionistas portadores de ações preferenciais devem ser deduzidos do lucro líquido a fim de se determinar o lucro disponibilizado aos acionistas portadores de ações ordinárias. Dessa forma, a remuneração dos acionistas portadores de ações preferenciais é de $\$ 25.000$ (1.000 ações preferenciais $\times \$$ 250 cada $\times 10 \%$ de remuneração) em relação ao resultado de $20 \times 1$.

Para fins de cálculo do denominador, é necessário calcular a média ponderada do número de ações em circulação durante o exercício a que se referem as demonstrações contábeis, conforme o quadro abaixo: 
Quadro 01 - Exemplo de cálculo da média ponderada de ações em circulação

\begin{tabular}{|l|c|c|c|}
\hline \multicolumn{1}{|c|}{ Item } & $\begin{array}{c}\text { Número de } \\
\text { ações } \\
\text { atualmente } \\
\text { em circulação }\end{array}$ & $\begin{array}{c}\text { Fração } \\
\text { do ano em } \\
\text { circulação }\end{array}$ & $\begin{array}{c}\text { Ações em circulação } \\
\text { em função do } \\
\text { período de tempo } \\
\text { em circulação }\end{array}$ \\
\hline Número de ações no início do exercício & 200.000 & $12 / 12$ & 200.000 \\
\hline Emissão de novas ações em 01/04X1 & 50.000 & $9 / 12$ & 37.500 \\
\hline $\begin{array}{l}\text { Emissão de novas ações pela subscrição de 12\% dos } \\
\text { dividendos declarados em 01/07/X1, referente as ações em } \\
\text { circulação desde 01/01/X1 }\end{array}$ & & $12 / 12$ & 24.000 \\
\hline $\begin{array}{l}\text { Emissão de novas ações pela subscrição de 12\% dos } \\
\text { dividendos declarados em 01/07/X1, referente às ações em } \\
\text { circulação desde 01/04/X1 }\end{array}$ & 24.000 & & \\
\hline Recompra de ações em 01/10/X1 & 6.000 & $3 / 12$ & $(10.000)$ \\
\hline $\begin{array}{l}\text { Média ponderada de ações ordinárias em circulação } \\
\text { durante o exercício }\end{array}$ & $(40.000)$ & & 2500 \\
\hline
\end{tabular}

Dessa forma, apresentam-se os seguintes Lucros por Ação Básicos (LPAB):

a) no Lucro Operacional

$$
=>\frac{\$ 281.000-\$ 25.000}{256.000}=\$ 1,00
$$

b) no Lucro líquido

$$
=>\frac{\$ 217.000-\$ 25.000}{256.000}=\$ 0,75
$$

Os números do LPAB acima devem ser evidenciados na demonstração do resultado do exercício a que se referem as demonstrações contábeis. A evidenciação de perdas extraordinárias de $\$ 0,25$ por ação (\$ 64.000 / 256.000 ações) deverá ser efetuada no corpo da demonstração do resultado ou em notas explicativas.

\subsubsection{Estrutura COMPLEXA DE CAPITAL}

As entidades que possuem uma estrutura complexa de capital apresentam instrumentos financeiros diversos com potencial dilutivo, ou seja, possuem o potencial de serem convertidos em ações ordinárias, reduzindo assim o LPA. Instrumentos financeiros diversos com potencial anti-dilutivo, ou seja, que aumentam o LPA, não são considerados para fins de cálculo do mesmo.

Uma entidade que apresentar uma estrutura complexa de capital deverá evidenciar tanto o Lucro por Ação Básico (LPAB) como o Lucro por Ação Diluído
(LPAD) no corpo da demonstração do resultado.

Para calcular o LPAD é necessário identificar todos os instrumentos financeiros com potencial dilutivo conversíveis em ações ordinárias emitidos pela entidade e calcular os efeitos desses no lucro líquido e no número de ações ordinárias em circulação.

Normalmente o LPAD é menor que o LPAB. Entretanto, podem ocorrer situações em que o LPAD e o LPAB são idênticos, em decorrência do fato de todos os instrumentos financeiros com potencial dilutivo se apresentarem como anti-dilutivos.

\subsubsection{IDENTIFICAÇÃo DOS INSTRUMENTOS FINANCEIROS POTENCIALMENTE DILUTIVEIS}

O SFAS 128 cita como exemplos para esse tipo de instrumentos as debêntures conversíveis, ações preferenciais conversíveis, opções de compra, bônus de subscrição e as ações ordinárias de dupla classe.

Nos instrumentos conversíveis em ações ordinárias, o seu portador recebe juros por parte da entidade que os emitiu.

As opções de compra e os bônus de subscrição são instrumentos que garantem a seus portadores o direito de adquirir ações ordinárias da entidade que os emitiu a um preço pré-determinado por um certo período de tempo.

As ações ordinárias de dupla classe normalmente remuneram seus portadores com dividendos diferenciados, de acordo com a classe de ações que os mesmos possuam, podendo essas ser conversíveis 
ou não em ações ordinárias simples.

\subsubsection{CÁlCULO dO LPAD}

Existem três métodos para se calcular o LPAD:

a) método two-class;

b) método treasury stock;

c) método if-converted.

O método two-class é utilizado nos casos em que a entidade tenha emitido instrumentos financeiros que garantam a seus portadores a participação nos resultados e ações ordinárias de dupla classe, porém não conversíveis em ações ordinárias. Nesse método, o lucro operacional (ou lucro líquido) deve ser reduzido pelo total de dividendos declarados no exercício a que se referem as demonstrações contábeis para cada classe de ações.

O método treasury stock é utilizado nos casos de ocorrência de bônus de subscrição e opções de compras, considerando-os como se tivessem sido exercidos, ou seja, convertidos em ações preferenciais no início do exercício, ou na data de sua emissão, se posterior. Os recursos que seriam obtidos pela conversão dos mesmos seriam utilizados para adquirir ações ordinárias da própria entidade, pela cotação média de mercado dos papéis durante o exercício a que se referem as demonstrações contábeis. Se o preço de exercício dos bônus de subscrição e das opções for maior que a cotação média de mercado dos papéis, não se deve considerar a conversão dos mesmos para fins de cálculo do LPAD, desde que os resultados dessas transações sejam anti-dilutivos.

Importante salientar que as transações acima descritas são apenas "virtuais", e aplicáveis às opções de compra e bônus de subscrição que foram emitidos em exercícios passados ou ao longo do exercício corrente e que não tenham sido exercidos até a data de encerramento das demonstrações contábeis. Caso esses instrumentos tivessem sido exercidos, ou seja, convertidos em ações ordinárias, essas novas ações entrariam no cômputo da média ponderada de ações ordinárias em circulação durante o exercício a que se referem as demonstrações contábeis.

O método if-converted é utilizado nas situações em que ocorram instrumentos financeiros que garantam a seus portadores o recebimento de remunerações (juros ou dividendos preferenciais) por parte da entidade que os emitiu. As remunerações atribuíveis aos portadores desse tipo de instrumentos, líquidas de impostos, não são consideradas no montante do lucro atribuível aos acionistas portadores de ações ordinárias, e a média ponderada de ações ordinárias em circulação durante o exercício a que se referem as demonstrações contábeis é ajustada, assumindose que a conversão das ações preferenciais ou dos outros instrumentos financeiros conversíveis tenha ocorrido no início do exercício, ou na data de emissão desses instrumentos, se posterior.

Com base no exposto acima, generaliza-se que o método if-converted é utilizado nos casos de instrumentos financeiros conversíveis, e o método treasury stock é utilizado no caso de opções de compra e bônus de subscrição. Entretanto, o SFAS 128 prevê algumas situações em que não se aplicam os métodos:

a) caso as opções e os bônus de subscrição emitidos contenham providências que permitam que dívidas ou outros instrumentos do emissor sejam oferecidos por todo o período de vigência das opções ou dos bônus, deverá ser utilizado o método if-converted;

b) no caso de as opções e os bônus de subscrição emitidos conterem exigências para que os recursos advindos de sua conversão sejam utilizados para quitar dívidas existentes da entidade, deverá ser utilizado o método if-converted;

c) no caso de instrumentos financeiros conversíveis que exijam alguma contraprestação monetária por parte de seu portador no ato de sua conversão, de tal forma que possam ser considerados equivalentes aos bônus de subscrição, deverá ser adotado o método treasury stock.

\subsubsection{EXEMPLO DE CÁLCULO DO LPAD EM UMA ESTRUTURA COMPLEXA DE CAPITAL}

a) Exemplo considerando o método treasury stock

O lucro líquido do exercício foi de $\$ 217.000$, e a média ponderada de ações ordinárias em circulação durante o exercício foi de 256.000 ações.

Dados adicionais:

- a remuneração das ações preferenciais cumulativas não conversíveis é de $10 \%$ (1.000 ações emitidas e em circulação durante todo o exercício, cotadas a $\$ 250$ cada);

- opções e bônus de subscrição para o exercício de 2.000 ações ordinárias cotadas a $\$ 12$ cada. 
A cotação média de mercado das ações ordinárias da entidade durante o exercício a que se referem as demonstrações contábeis foi de $\$ 20$, sendo que as opções e os bônus permaneceram em circulação durante todo o exercício.

\section{O primeiro passo é o cálculo do LPAB:}

$$
\angle P A B=\frac{L L-D P}{M P A}=\frac{\$ 217.000-\$ 25.000}{256.000}=\$ 0,75
$$

Onde:

- LPAB => lucro por ação básico;

- $L L$ => lucro líquido do exercício;

- DP => remuneração atribuída às ações preferenciais;

- MPA => média ponderada de ações ordinárias em circulação durante o exercício.

O passo seguinte é calcular o LPAD. Para esse exemplo, as opções e os bônus de subscrição são os únicos instrumentos potencialmente dilutivos. Importante salientar que apenas os instrumentos dilutivos, ou seja, aqueles em que a cotação de mercado é maior que o preço de exercício, são incluídos na base de cálculo do LPAD. Assim, os ajustes no denominador a serem efetuados são os seguintes:

- os recursos considerados como se advindos do exercício das opções e bônus de subscrição montam em \$24.000;

- 2.000 ações ordinárias consideradas como se fossem emitidas no início do exercício;

-1.200 ações ordinárias consideradas como se fossem recompradas (\$24.000 / \$20);

- 800 ações consideradas como se emitidas e não recompradas.

Essas 800 ações são consideradas como sendo os reflexos dos instrumentos financeiros potencialmente dilutivos.

Dessa forma têm-se:

$$
L P A D=\frac{L L-D P}{M P A+I D}=\frac{\$ 217000-\$ 25.000}{256.000+800}=\$ 0,7477
$$

Onde:

- LPAD => lucro por ação diluído;

- LL => lucro líquido do exercício;

- DP => remuneração atribuída às ações preferenciais;
- MPA => média ponderada de ações ordinárias em circulação durante o exercício;

- ID => reflexos dos instrumentos financeiros potencialmente dilutivos.

b) Exemplo considerando o método if-converted

O lucro líquido do exercício foi de $\$ 217.000$, e a média ponderada de ações ordinárias em circulação durante o exercício foi de 256.000 ações.

Dados adicionais:

- remuneração dos instrumentos financeiros conversíveis de $8 \%$, incidindo IR de $25 \%$. Foram emitidos 200 títulos, cada um conversível em 120 ações ordinárias, e sua emissão ocorreu pelo valor nominal de $\$ 1.000$ cada. Nenhum título foi convertido durante o exercício a que se referem as demonstrações contábeis;

- remuneração das ações preferenciais cumulativas conversíveis de $10 \%$. Foram emitidas 1.000 ações, as quais permaneceram em circulação durante todo o exercício, ao valor nominal de \$ 250 cada. Cada ação preferencial é conversível em 40 ações ordinárias; entretanto, nenhuma foi convertida durante o exercício a que se referem as demonstrações contábeis.

O primeiro passo é o cálculo do LPA básico, o qual já foi calculado anteriormente, e é de $\$ 0,75$ por ação ordinária.

O passo seguinte é o cálculo do LPAD. Os instrumentos financeiros conversíveis são considerados como se tivessem sido convertidos no início do exercício. Os efeitos de tal procedimento são os seguintes:

- caso essa conversão tivesse realmente ocorrido no início do período, a entidade não teria incorrido em uma despesa com juros referente à remuneração desses instrumentos de $\$$ 16.000 (\$1.000 x 200 títulos $\times 8 \%$ de remuneração). Sobre essa despesa de juros deveriam ser considerados os efeitos da deseconomia de IR, à alíquota de $25 \%$. Assim, os efeitos líquidos seriam de $\$ 16.000$ menos $25 \%$, ou seja, \$12.000;

- da mesma forma, a entidade teria emitido 24.000 novas ações ordinárias, pois cada um dos 200 títulos emitidos seria convertido em 120 ações ordinárias. 
Dessa forma, tem-se o seguinte:

$$
L P A D=\frac{L L-D P+D O}{M P A+N A}=\frac{\$ 217.000-\$ 25.000+\$ 12.000}{256.000+24.000}=\$ 0,7286
$$

Onde:

- LPAD => lucro por ação diluído;

- LL => lucro líquido do exercício;

- DP => remuneração atribuída às ações preferenciais;

- DO => despesas financeiras líquidas que não teriam ocorrido (16.000 - IR 25\%);

- MPA => média ponderada de ações ordinárias em circulação durante o exercício;

- NA => ações ordinárias que seriam emitidas pela conversão dos títulos conversíveis.

Para determinar-se o efeito dilutivo decorrente da conversão das ações preferenciais, considera-se que essa conversão tenha ocorrido no início do exercício.
Os efeitos para tal procedimento são os seguintes:

- se as ações preferenciais tivessem sido convertidas em ações ordinárias no início do exercício a que se referem as demonstrações contábeis, não teria havido a ocorrência da remuneração das ações preferenciais de $\$ 25.000$ (1.000 ações x $\$ 250$ cada x 10\%);

- da mesma forma, a entidade teria emitido e posto em circulação 40.000 novas ações ordinárias, uma vez que cada uma das 1.000 ações preferenciais existentes é conversível em 40 ações ordinárias.

Assim tem-se:

$$
L P A D=\frac{L L+D O}{M P A+N A+A P}=\frac{\$ 217.000+\$ 12.000}{256.000+24.000+40.000}=\$ 0,7156
$$

Onde:

- LPAD => lucro por ação diluído;

- LL => lucro líquido do exercício;

- DO => despesas financeiras líquidas que não teriam ocorrido (16.000 - IR 25\%);

- MPA => média ponderada de ações ordinárias em circulação durante o exercício;

- NA => ações ordinárias que seriam emitidas pela conversão dos títulos conversíveis;

- AP => ações ordinárias que seriam emitidas pela conversão das ações preferenciais.

Assim, o LPAD, considerando-se tanto os efeitos dos títulos conversíveis como as ações preferenciais conversíveis, é de $\$ 0,7156$ por ação ordinária. Nesse exemplo, foi considerado que as conversões teriam ocorrido no início do exercício a que se referem as demonstrações contábeis; entretanto, podem ocorrer situações em que será necessário considerar as conversões como se ocorridas em outras datas. Dessa forma, seria necessário ajustar tanto o numerador quanto o denominador da equação do LPA à data da conversão.

\subsubsection{INCLUSÕES E EXCLUSÕES DO CÁLCULO Do LPAD}

O cálculo do LPAD deve incluir, sempre que possível, as opções de venda, contratos de compra futu- ra e outros tipos de contratos que estabeleçam que a entidade irá recomprar suas próprias ações, caso os efeitos desses itens sejam dilutivos. Se durante o exercício a que se referem as demonstrações contábeis o preço de exercício desses contratos exceder a cotação média de mercado das ações ordinárias, deverá ser utilizado o método treasury stock, de tal forma que:

a) emissões de novas ações ordinárias devem ser consideradas como se tivessem ocorrido no início do exercício a que se referem as demonstrações contábeis, pela cotação média de mercado no exercício, de tal forma que sejam reconhecidos recursos suficientes para satisfazer as cláusulas dos contratos;

b) os recursos obtidos com a emissão desses contratos devem ser utilizados para satisfazer as cláusulas constantes do contrato, ou seja, a recompra das ações;

c) o denominador do cálculo do LPAD deve conter o acréscimo de ações ordinárias, ou seja, a diferença entre o número de ações consideradas como se emitidas e o número de ações consideradas como se recompradas. 
3.2. Apresentação de Informações adicionais

O SFAS 128 faz algumas exigências adicionais em relação ao LPA e LPAD:

a) caso a entidade apresente em sua demonstração do resultado a linha "Lucro Operacional", o LPAB e o LPAD deverão ser calculados para esta e para o Lucro Líquido. Caso a empresa apresente apenas a linha "Lucro Líquido", tal exigência não se faz presente. É necessária a reconciliação do numerador e do denominador do LPAB e LPAD obtido para o Lucro Operacional e para o Lucro Líquido, se aplicável;

b) caso a entidade esteja com o pagamento de dividendos e remunerações atribuíveis aos acionistas portadores de ações preferenciais em atraso, ela deverá evidenciar o montante em atraso, bem como todos os seus efeitos sobre o cálculo do LPAB e LPAD;

c) em situações em que ocorra split de ações após a data de encerramento das demonstrações contábeis de determinado exercício, porém antes da publicação do relatório anual, é exigido o ajuste retroativo do número de ações em circulação. Nesses casos deverá ser evidenciado tanto o número de ações ordinárias em circulação após o split, bem como o número de ações ordinárias em circulação anteriormente ao split. Tal exigência também se aplica no caso de reverse split;

d) no caso de uma entidade evidenciar operações em descontinuidade, itens extraordinários ou efeitos cumulativos de mudanças em suas práticas contábeis, ela deverá apresentar os efeitos desses itens sobre o cálculo do LPAB e LPAD no corpo da demonstração do resultado do exercício a que se referem as demonstrações contábeis, ou em notas explicativas;

e) efeitos das remunerações atribuídas aos acionistas portadores de ações preferenciais;

f) instrumentos financeiros com potencial dilutivo do LPAB em exercícios futuros, porém não inclusos no cálculo do LPAD para o exercício a que se referem as demonstrações contábeis;

g) fatos relevantes que venham a alterar a quantidade de ações ordinárias em circulação após a data de encerramento das demonstrações contábeis.

\section{NORMAS DO IASC}

A Norma Internacional de Contabilidade que trata do lucro por ação é a IAS $33^{2}$. O objetivo da norma é a prescrição de princípios para a determinação e apresentação do Resultado por Ação (RPA), visando a uma melhor comparabilidade do desempenho entre diferentes entidades em um mesmo exercício e entre diferentes exercícios de uma mesma entidade.

O foco principal da norma é o denominador do cálculo do RPA, mesmo que as diferentes políticas contábeis adotadas pelas empresas na apuração dos resultados causem limitações nos dados que formam o resultado por ação.

A norma aplica-se a todas as entidades constituídas sob a forma de sociedades por ações, independente do fato de terem ou não suas ações negociadas em bolsas de valores.

\subsection{TeRminologia dA IAS $\mathbf{3 3}$}

A Norma Internacional de Contabilidade IAS 33 define alguns termos, a saber:

- ação ordinária => instrumento patrimonial que é subordinado a todas as outras classes de instrumentos patrimoniais;

- ação ordinária potencial => é um instrumento financeiro ou outro contrato que garante a seu portador o direito de receber ações ordinárias;

- garantias ou opções de compra => são instrumentos financeiros que garantem a seu possuidor o direito de comprar ações ordinárias;

- instrumento financeiro => é um contrato que origina tanto um ativo financeiro em uma entidade como um passivo financeiro ou um instrumento patrimonial em outra entidade;

- instrumento patrimonial => é qualquer contrato que evidencie uma participação residual nos ativos de uma entidade após a dedução de todos os seus passivos;

- valor justo (fair value) => é o montante pelo qual um ativo poderia ser transacionado, ou um passivo quitado, entre partes conhecedoras do assunto e dispostas a negociar numa transação sem favorecimentos.

\footnotetext{
${ }^{2}$ IAS é a sigla de International Accouting Standards, ou, traduzido para o português, Norma Internacional de Contabilidade
} 


\subsection{Resultado por aÇão básico (RPAB)}

Calculado mediante a divisão do lucro ou prejuízo líquido do exercício a que se referem as demonstrações contábeis atribuível aos acionistas ordinários, pela média ponderada da quantidade de ações ordinárias em circulação naquele exercício.

\subsubsection{Resultado}

Trata-se do resultado contábil apurado na respectiva demonstração, através do confronto das receitas do exercício, com as despesas e custos, e deduzidos os dividendos preferenciais. Os dividendos preferenciais deduzidos do resultado líquido podem ser:

- valor de quaisquer dividendos sobre ações pre- ferenciais não cumulativas declarados em relação ao exercício; e

- valor total dos dividendos correspondentes às ações preferenciais cumulativas do exercício, que tenham ou não sido declarados. O valor dos dividendos preferenciais do exercício não inclui o montante de quaisquer dividendos de ações preferenciais cumulativas pagos ou declarados durante 0 período em relação aos períodos anteriores.

\subsubsection{Quantidade de Ações}

No RPAB, a forma de cálculo da quantidade média ponderada de ações ordinárias em circulação é demonstrada no exemplo abaixo:

Quadro 2 - Exemplo de cálculo da quantidade média ponderada de ações

\begin{tabular}{|l|l|c|c|c|}
\hline Data & Item & $\begin{array}{c}\text { Ações } \\
\text { emitidas }\end{array}$ & $\begin{array}{c}\text { Ações em } \\
\text { tesouraria }\end{array}$ & $\begin{array}{c}\text { Ações em } \\
\text { circulação }\end{array}$ \\
\hline $01 / 01 / X 1$ & Saldo inicial & 2200 & 330 & 1870 \\
\hline $31 / 05 / X 1$ & Emissão de novas ações contra caixa & 900 & 0 & 2770 \\
\hline $01 / 12 / X 1$ & Compra em dinheiro de ações para tesouraria & 0 & 300 & 2470 \\
\hline $31 / 12 / X 1$ & Saldo final & 3100 & 630 & 2470 \\
\hline $\begin{array}{l}\text { Cômputo da média ponderada: } \\
(1870 \times 5 / 12)+(2770 \times 6 / 12)+(2470 \times 1 / 12)=2370 \text { ações }\end{array}$ \\
\hline
\end{tabular}

No caso de combinações de empresas (business combination), o tratamento a ser adotado varia em função do tipo de combinação ocorrida.

Se for uma aquisição (purchase), as ações ordinárias emitidas como parte do valor de compra são incluídas na média ponderada de ações desde a data da aquisição, já que o adquirente incorpora o resultado das operações do adquirido na sua demonstração do resultado desde a data da aquisição. Em se tratando de uma fusão (pooling of interest), as ações ordinárias emitidas como parte da combinação são incluídas no cálculo da quantidade média ponderada de ações em todos os exercícios apresentados, pelo fato de as demonstrações contábeis da empresa combinada serem preparadas como se sempre tivessem existido.

\subsubsection{AJUSTES NA QUANTIDADE MÉDIA PONDERADA DE AÇÕES}

Durante o exercício em questão e para todos os exercícios apresentados, deve-se ajustar a quantidade média ponderada de ações em circulação, pelos eventos que alterem o número de ações ordinárias em circulação sem uma correspondente mudança nos recursos financeiros, tais como:

- uma capitalização ou emissão de bonificação, conforme demonstrado no quadro 2 (conhecida em alguns países como dividendo em ações);

- um componente de bonificação em qualquer outra emissão, por exemplo um componente de bonificação no lançamento de direitos para os acionistas atuais, assim como demonstrado no quadro 3;

- uma divisão (split) de ações; e

- uma reversão de divisão de ações, ou seja, uma consolidação de ações (reverse split). 
Quadro 3 - Exemplo de Emissão de Bonificação

\begin{tabular}{|l|c|}
\hline Lucro líquido X0 & 220 \\
\hline Lucro líquido X1 & 700 \\
\hline Ações em circulação até 30/09/X0 & 250 \\
\hline Emissão de 250 bonificações em 01/10/X0 & $\begin{array}{r}\text { 2 ações ordinárias para cada ação ordinária em } \\
\text { circulação em 30/09/X1 (250 x } 2=500 \text { novas ações })\end{array}$ \\
\hline Lucro por ação em X1 & $700 /(250+500)=0,93$ \\
\hline Lucro por ação em X0 ajustado & $220 /(250+500)=0,29$ \\
\hline
\end{tabular}

Sendo a emissão da bonificação uma emissão sem contrapartida remunerada, a mesma é tratada como se ocorrida fosse no início de X0.

\subsection{Resultado Por ação diluído (RPAD)}

No cálculo do RPAD, tanto a quantidade média ponderada de ações em circulação, assim como o resultado líquido atribuível aos acionistas ordinários devem ser ajustados pelos efeitos de todas as ações ordinárias potenciais dilutivas (vide quadro 4). Dentre os ajustes ao resultado líquido, encontram-se os efeitos fiscais, como relacionado a seguir:

- quaisquer dividendos sobre ações ordinárias potenciais dilutivas que tenham sido deduzidos para chegar ao lucro líquido do período atribuível aos acionistas ordinários, calculado conforme o parágrafo $11^{3}$ da IAS 33;

- juros reconhecidos do período para as ações ordinárias potenciais dilutivas; $\mathrm{e}$

- quaisquer outras mudanças na receita ou despesa que resultariam da conversão das ações ordinárias potenciais dilutivas.

\section{Quadro 4 - Exemplo de Lançamento de Direitos}

\begin{tabular}{|l|l|}
\hline Lucro Líquido & $\mathrm{X} 0=1.200 ; \mathrm{X} 1=1.600 ; \mathrm{X} 2=1.800$ \\
\hline Ações em circulação antes do lançamento de direitos & 600 ações \\
\hline \multirow{2}{*}{ Direitos lançados } & $\begin{array}{l}\text { Uma nova ação para cada cinco em circulação (100 novas ações) } \\
\text { Preço de exercício: } 6,00\end{array}$ \\
& Data final para exercício dos direitos: $01 / 03 / \mathrm{X} 1$ \\
\hline \multicolumn{2}{|l|}{ Valor justo de uma ação ordinária imediatamente antes do exercício em 01/03/X1 = 12,00 } \\
\hline \hline
\end{tabular}

\section{Cômputo teórico por ação ex-direitos}

Valor justo de todas as ações em circulação + montante total recebido do exercício de direitos Número de ações em circulação antes do exercício + número de ações emitidas pelo exercício

$$
\frac{(12,00 \times 600)+(6,00 \times 100 \text { ações })}{600 \text { ações }+100 \text { ações }}
$$

\begin{tabular}{|c|c|c|c|}
\hline Cômputo do resultado por ação & XO & $\mathbf{X} 1$ & $\mathrm{X} 2$ \\
\hline RPA X0 Segundo divulgado originalmente $=1.200 / 600$ ações & 2,00 & - & - \\
\hline RPA X0 corrigido para o lançamento de direitos: $1.200 /(600$ ações x 1,08) & 1,86 & - & - \\
\hline $\begin{array}{l}\text { RPA incluindo os efeitos do lançamento de direitos } \\
\qquad 1.600\end{array}$ & & & \\
\hline$(600$ ações $\times 1,08$ x 2/12) + (700 x 10/12) & - & 2,32 & - \\
\hline RPA X2 = $1.800 / 700$ ações & - & - & 2,57 \\
\hline
\end{tabular}

Valor teórico por ação ex-direitos $=11,14$

\footnotetext{
${ }^{3}$ Trata da forma de cálculo do RPAB.
} 
A seguir, é apresentado um exemplo de cálculo do resultado por ação diluído, no caso dos bônus conversíveis:

\section{Quadro 5 - Exemplo de Cálculo do Resultado por Ação Diluído, Considerando-se os Bônus Conversíveis}

\begin{tabular}{|l|r|}
\hline Lucro Líquido & 1.006 \\
\hline Ações ordinárias em circulação & 1.100 \\
\hline Lucro básico por ação & 1,00 \\
\hline Bônus conversíveis & 150 \\
\hline Cada lote de 10 bônus é conversível em 4 ações ordinárias & 10 \\
\hline Despesa de juros do ano corrente referentes os bônus & 6 \\
\hline Impostos correntes e diferidos relacionados com essa despesa de juros & $1.006+10-6=1010$ \\
\hline Lucro líquido ajustado & $10 \times 4=40$ \\
\hline Quantidade de ações ordinárias resultante da conversão dos bônus & $1.100+40=1.140$ \\
\hline Número de ações ordinárias utilizado para computar o resultado diluído por ação & $1.010=0,89$ \\
\hline Lucro diluído por ação & 1.140 \\
\hline
\end{tabular}

Ainda em relação ao cálculo do RPAD, a IAS 33 determina que o número de ações ordinárias deve ser a quantidade média ponderada de ações ordinárias calculada conforme previsto em seu texto, acrescida da quantidade média ponderada de ações ordinárias que seriam emitidas para a conversão de todas as ações ordinárias potenciais dilutivas em ações ordinárias.

Presume-se que as ações ordinárias potenciais dilutivas serão convertidas em ações ordinárias no início do período ou, se posteriormente, na data de emissão das ações ordinárias potenciais. A entidade deve assumir o exercício de opções dilutivas e outras ações ordinárias potenciais dilutivas quando se trata do cálculo do RPAD. A disponibilidade presumida dessas emissões deve ser considerada como tendo sido recebida pela emissão das ações a valor justo. A diferença entre a quantidade de ações emitidas e o número de ações que teriam sido emitidas a valor justo deve ser tratada como uma emissão de ações ordinárias sem pagamento, conforme demonstrado abaixo:

\section{Quadro 6 - Efeitos de Opções de Ações sobre o Resultado Diluído por Ação}

\begin{tabular}{|c|c|c|c|c|}
\hline \multicolumn{3}{|l|}{ Resultado líquido do ano X1 } & \multicolumn{2}{|r|}{1.300 .000} \\
\hline \multicolumn{3}{|c|}{ Quantidade média ponderada de ações ordinárias em circulação durante o ano X1 } & \multicolumn{2}{|c|}{550.000 ações } \\
\hline \multicolumn{3}{|l|}{ Valor justo médio de uma ação ordinária durante o ano X1 } & & 25,00 \\
\hline \multicolumn{3}{|c|}{ Quantidade média ponderada de ações com opção durante o ano X1 } & \multicolumn{2}{|c|}{150.000 ações } \\
\hline \multicolumn{3}{|l|}{ Preço de exercício para as ações com opção durante o ano X1 } & & 20,00 \\
\hline Cômputo do resultado por ação & Por Ação & \multicolumn{2}{|c|}{ Resultado } & Ações \\
\hline Resultado líquido do ano X1 & - & \multicolumn{2}{|c|}{1.300 .000} & - \\
\hline Média ponderada de ações em circulação durante o ano X1 & & & & 550.000 \\
\hline Resultado básico por ação & 2,36 & \multicolumn{2}{|c|}{-} & - \\
\hline Número de ações com opção & - & \multicolumn{2}{|c|}{-} & 150.000 \\
\hline $\begin{array}{l}\text { Número de ações que teriam sido emitidas a valor justo: } \\
(150.000 \times 20,00) / 25,00\end{array}$ & & & & $(120.000)$ \\
\hline Resultado diluído por ação & 2,24 & 1.30 & 000 & 580.000 \\
\hline
\end{tabular}

No caso de ocorrerem ações ordinárias potenciais dilutivas, estas devem ser tratadas como sendo dilutivas na hipótese em que sua conversão em ações ordinárias diminuir o resultado líquido por ação decorrente das operações ordinárias.
Os quadros 7 e 8 demonstram os cálculos a serem realizados, para se saber se os títulos são ou não dilutivos, além da ordem na qual incluir títulos dilutivos no cálculo do número médio ponderado de ações. 


\section{Quadro 7 - Determinação da ordem na qual incluir títulos dilutivos no cálculo do número médio ponderado de ações}

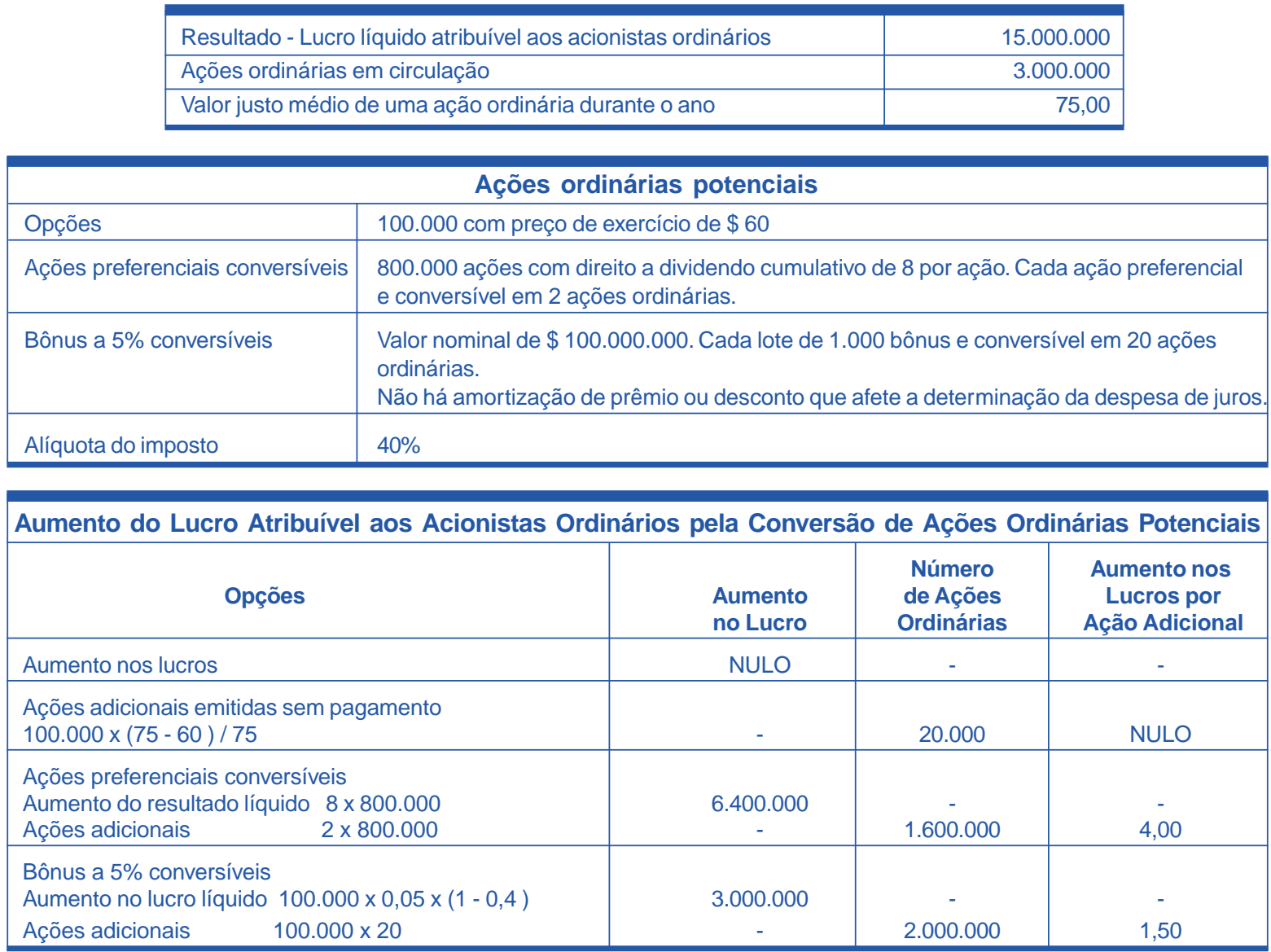

Quadro 8 - Cômputo do Resultado por Ação

\begin{tabular}{|l|c|c|c|c|}
\hline \multicolumn{1}{|c|}{ Discriminação } & $\begin{array}{c}\text { Lucro Líquido } \\
\text { Atribuível }\end{array}$ & $\begin{array}{c}\text { Ações } \\
\text { Ordinárias }\end{array}$ & Por Ação & Efeito \\
\hline Segundo divulgado & 15.000 .000 & 3.000 .000 & 5,00 & \\
\hline Opções & & 20.000 & & Dilutivo \\
\hline Sub total & $\mathbf{1 5 . 0 0 0 . 0 0 0}$ & $\mathbf{3 . 0 2 0 . 0 0 0}$ & $\mathbf{4 . 9 7}$ & \\
\hline Bônus a 5\% conversíveis & 3.000 .000 & 2.000 .000 & & Dilutivo \\
\hline Sub total & $\mathbf{1 8 . 0 0 0 . 0 0 0}$ & $\mathbf{5 . 0 2 0 . 0 0 0}$ & $\mathbf{3 , 5 9}$ & \\
\hline Ações preferenciais conversíveis & 6.400 .000 & 1.600 .000 & & Não Dilutivo \\
\hline Total & $\mathbf{2 4 . 4 0 0 . 0 0 0}$ & $\mathbf{6 . 6 2 0 . 0 0 0}$ & $\mathbf{3 , 6 9}$ & (2.000 \\
\hline
\end{tabular}

Sendo que o resultado diluído por ação é aumentado quando se consideram as ações preferenciais conversíveis (de 3,59 para 3,69), as ações preferenciais conversíveis são não dilutivas e são ignoradas no cálculo do resultado diluído por ação. Assim, o resultado diluído por ação é 3,59.

Este exemplo não ilustra a classificação, requerida pela NIC 32, dos instrumentos financeiros conversíveis entre passivos e patrimônio líquido ou a classificação dos correspondentes juros e dividendos entre despesas e patrimônio líquido.

\subsection{REAJUSTE}

A norma estabelece que, em determinadas situações, os cálculos do RPAB e RPAD de todos os exercícios divulgados devem ser ajustados retroativamente. Isto se aplica naqueles casos em que a quantidade de ações ordinárias ou potenciais aumenta como conseqüência de uma capitalização, emissão de bônus, divisão de ações (share split), ou diminui como resultado de uma aglomeração de ações (reverse share split).

É previsto ainda que, se tais alterações acontecerem após a data de encerramento das demonstrações contábeis, porém antes de sua divulgação, os cálculos dos RPAB e RPAD para todos os exercícios apresentados devem estar baseados no novo número de ações. 
O reajuste do RPAD de qualquer exercício anterior apresentado não ocorrerá no caso de mudanças nas premissas utilizadas, ou pela conversão de ações ordinárias potenciais em ações ordinárias em circulação.

Há o incentivo para que as entidades divulguem as transações com ações ordinárias ou ações ordinárias potenciais, diferentes das emissões por capitalização e divisão de ações, que acontecerem após a data de encerramento das demonstrações contábeis, quando são de tal importância que a não divulgação afetaria a capacidade dos usuários das demonstrações contábeis para fazer avaliações e tomar decisões apropriadas. A seguir citam-se alguns exemplos de tais operações:

- a emissão de ações integralizadas em dinheiro;

- a emissão de ações quando os fundos são usados para resgatar títulos de dívida ou ações preferenciais em circulação na data do balanço;

- resgate de ações ordinárias em circulação;

- a conversão ou exercício de ações ordinárias potenciais, em circulação na data do balanço, em ações ordinárias;

- a emissão de garantias de ações, opções ou títulos conversíveis; e

- a realização de condições que resultariam na emissão de ações de emissão contingente.

\subsection{ApresentaçÃo (disclosure)}

Para a apresentação de seus resultados, a entidade deverá apresentar os RPAB e RPAD no corpo da demonstração do resultado, para cada classe de ação ordinária, para todos os exercícios apresentados no conjunto das demonstrações contábeis.

Tal procedimento deve ser adotado também no caso dos resultados serem negativos.

Pela norma, as entidades devem divulgar o seguinte:

- os montantes usados como numeradores no cálculo dos RPAB e RPAD; e uma reconciliação desses valores com o lucro ou prejuízo líquido do exercício; e

- a quantidade média ponderada de ações ordinárias usada como denominador no cálculo dos RPAB e RPAD e uma reconciliação entre os próprios denominadores.

\section{Considerações finaIS}

Neste trabalho analisaram-se as normas contábeis referentes ao Lucro (Resultado) por Ação. Apresentaram-se, com exemplos de cálculo, nas hipóteses básicas e complexas, as normas aplicáveis ao assunto emanadas do Financial Accounting Standards Board (FASB), dos Estados Unidos, e pelo International Accounting Standards Committee (IASC), em relação às normas internacionais. Também se demonstraram alguns aspectos em relação à situação brasileira.

O foco de concentração do trabalho, ou seja, a norma norte americana e a norma internacional, se justifica pelo fato de que os órgãos competentes, FASB e IASC, respectivamente, publicaram normas de contabilidade voltadas exclusivamente ao assunto, abrangendo conceitos, formas de cálculo e aspectos de disclosure.

No Brasil há muito pouco ou quase nenhum material publicado sobre o assunto. Conforme foi visto, nem mesmo por parte do Conselho Federal de Contabilidade existe uma regulamentação acerca do assunto, de tal forma que existe uma grande divergência de tratamento por parte das empresas quando do cálculo e apresentação do Lucro por Ação.

Somente a publicação de estudos e trabalhos sobre o assunto em revistas técnicas voltadas para a área de Contabilidade e Finanças possibilitará um maior debate em torno do mesmo por parte dos profissionais contábeis no país. Dessa forma, tornamse necessários estudos mais aprofundados, de forma que sejam publicados mais artigos ou trabalhos sobre o Lucro por Ação, contribuindo assim para a solidificação do conhecimento contábil.

\section{REFERÊNCIAS BIBLIOGRÁFICAS}

CONSELHO FEDERAL DE CONTABILIDADE. Princípios fundamentais de contabilidade e normas brasileiras de contabilidade. 2. ed. Brasília: CFC, 2000.

DELANEY, Patrick R., EPSTEIN, Barry J., ADLER, James R., FORAN, Michael F. GAAP2000: Interpretation and application of generally accepted accounting principles 2000. New York: John Wiley \& Sons, 2000.

HENDRIKSEN, Eldon S., VAN BREDA, Michael F. Teoria da contabilidade. São Paulo: Atlas, 1999.
IBRACON, Normas internacionais de contabilidade 1997. São Paulo: IBRACON, 1998.

INTERNATIONAL ACCOUNTING STANDARDS COMMITTEE. International accounting standards 2000. London: IASC, 2000.

IUdíCIBIUS, Sérgio de. MARTINS, Eliseu, GELBCKE, Ernesto Rubens. Manual de contabilidade das sociedades por ações: aplicável também às demais sociedades. São Paulo: Atlas, 1995. 